\title{
Causas de muerte en pacientes con un injerto renal funcionante. ¿Han ocurrido cambios en las últimas décadas?
}

\author{
JORGE VEGA ${ }^{1,2,3}$, CHRISTIAN VIDELA $^{3}$, HERNÁN BORJA ${ }^{3}$, \\ HELMUTH GOECKE ${ }^{1,2,4}$, FELIPE MARTÍNEZ ${ }^{1,2}$, PABLO BETANCOUR ${ }^{1,2}$
}

\section{Causes of death with a functioning graft among kidney allograft recipients}

Background: Death with a functioning graft (DWGF) is now one of the main causes of renal transplant (RTX) loss. Aim: To determine whether the causes of DWGF, characteristics of donors and recipients and complications of $R T x$ have changed in the last two decades. Subjects and Methods: Cooperative study of a cohort of 418 kidney grafts performed between 1968 and 2010. Patients were divided into two groups according to whether their kidney transplants were performed between 1968 and 1992 (Group 1) or 1993 and 2010 (Group 2). Results: Sixty eight patients experienced DWGF. Infections were the leading cause of DWGF in both groups (38 and $41 \%$, respectively), followed by cardiovascular diseases (24 and 23\% respectively), gastrointestinal disorders (21 and 26\% respectively) and cancer (17 and 10\% respectively). There were no significant differences in causes of death between the two groups according to the time elapsed since the renal transplantation. In patients in Group 1, the interval between diagnosis of renal failure and dialysis (HD) and the interval between the start of HD and kidney transplantation were significantly lower than in Group 2. The former had also an increased number of acute rejections in the first five years of kidney transplantation $(p<0.001)$. In Group 2, patients more often received their kidneys from deceased donors, had previous kidney transplantation, higher rate of antibodies to a panel of lymphocytes and an increased incidence of cardiovascular disorders after five years of RTx. Conclusions: The proportion of graft loss due to DWGF has increased over the last 2 decades, but its causes have not changed significantly. Infections are the most common causes of DWGF followed by cardiovascular and digestive diseases.

(Rev Med Chile 2012; 140: 295-304).

Key words: Immunosuppressive agents; Kidney transplantation; Morbidity; Mortality; Prognosis; Treatment outcome.

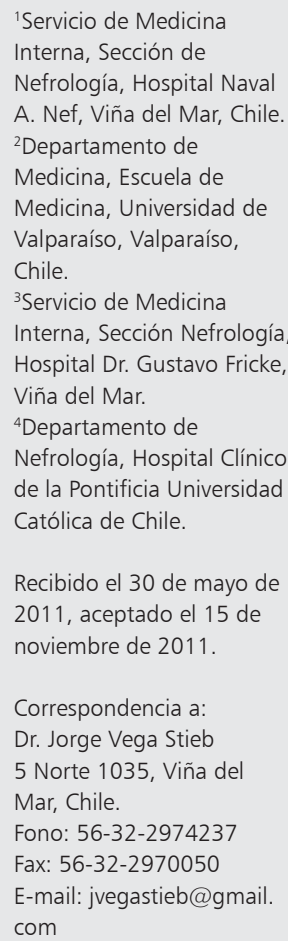

la intervención, resultando en una pérdida anual de 3-5\% de los injertos ${ }^{1-7}$. Si bien la mortalidad de los pacientes trasplantados es inferior a la de los sujetos que permanecen en DC, su sobrevida es inferior a la de controles pareados por edad en la población general ${ }^{1-4,8-9}$. La mortalidad es 14,7 veces mayor durante el primer año del TxR y 4,4 veces mayor después de este período ${ }^{1,10}$.

Los objetivos de esta investigación fueron conocer si las causas de MCRF han cambiado en las 
últimas dos décadas. También, si las características de donantes y receptores y las complicaciones aparecidas durante la evolución de los trasplantes han tenido cambios durante este período.

\section{Sujetos y Métodos}

Trabajo cooperativo que incluyó a los pacientes trasplantados de riñón en los últimos 42 años (agosto de 1968 a octubre de 2010) en los hospitales: Dr. Gustavo Fricke de Viña del Mar, Naval Almirante Nef de Valparaíso, Clínica Reñaca y Naval de Viña del Mar. También incluyó a los pacientes trasplantados en otros hospitales del país o del extranjero que continuaron sus controles en forma regular con alguno de los nefrólogos de dichos hospitales. El estudio incluyó a $418 \mathrm{TxR}$ efectuados en 398 pacientes.

Los criterios de inclusión de un paciente a este estudio fueron:

1. Que el TxR haya sido efectuado en alguno de los 4 hospitales y si se efectuó en otro nosocomio, que el paciente haya tenido al menos 2 controles con alguno de sus nefrólogos.

2. Que el paciente haya fallecido con un riñón funcionante.

Los criterios de exclusión fueron:

1. No contar con información suficiente sobre la evolución del paciente o de su estado al 1 de noviembre de 2010.

2. Haber sido sometido a un trasplante multiorgánico.

De los 418 trasplantes renales, 11 fueron excluidos por falta de información y ninguno por trasplante multiorgánico (diez pacientes del primer período y 1 del segundo período). De 387 sujetos incluidos, 68 cumplieron con criterios de muerte con riñón funcionante (MCRF). Ellos se agruparon en 2 grupos dependiendo de si el TxR se efectuó entre 1968-1992 (Grupo 1) o 1993-2010 (Grupo 2). El año elegido para la separación en 2 grupos fue el de la incorporación de ciclosporina en el esquema inmunosupresor de todos los trasplantados: 1993.

Se registraron los datos demográficos y características inmunológicas de donantes y receptores, información relevante sobre la nefropatía, etapa dialítica, inmunosupresión utilizada, evolución del trasplante, complicaciones y el estado del paciente al final del seguimiento.

Para la estimación de la velocidad de filtración glomerular (eVFG), de las fórmulas más frecuentemente empleadas utilizamos la fórmula de MDRD-4 $4^{11-14}$. Se definió como MCRF cuando la muerte no fue precedida del retorno a diálisis (o de su rechazo, si ella estaba indicada) o de nefrectomía del injerto. Se consideró como función renal retardada cuando se requirió de al menos una sesión de diálisis durante la primera semana del TxR.

Estadística. Para el análisis estadístico se utilizó frecuencias, porcentajes, mediana y rango intercuartil según correspondiera; para determinar la distribución de las variables cuantitativas se graficaron los datos y se usó la prueba de normalidad de Shapiro-Wilk. El análisis inferencial bivariado se realizó mediante las prueba estadística de $\chi^{2}$ (Chicuadrado) con corrección de Yates para variables cualitativas cuando fue necesario y la prueba de Mann-Whitney para variables cuantitativas. Se consideró significativo un valor de $\mathrm{p}<0,05$.

\section{Resultados}

Las características demográficas de los receptores, tipo de donante, número de injertos recibidos, proporción de diabéticos y evolución de los injertos en cada grupo se muestran en la Tabla 1. Los pacientes del Grupo 1 tuvieron un total de 1.366 años de observación (10,34 años por paciente) y los del Grupo 2, 1.852 años de observación (7,75 años por paciente) $(\mathrm{p}<0,001)$.

Las curvas de sobrevida (Kaplan-Meier) en ambos grupos de trasplantados renales fue similar (Figura 1).

De los 68 pacientes con MCRF, 29 fueron trasplantados durante el primer período y 39 durante el segundo. La duración de sus injertos, edad al fallecimiento, lugar de muerte y función renal durante su evolución se muestran en Tabla 2.

\section{Causas de muerte con riñón funcionante}

Las causas de muerte más frecuentes fueron las infecciones $(39,7 \%)$, seguidas por las enfermedades cardiovasculares (ECV) $(23,5 \%)$, patologías digestivas $(23,5 \%)$ y cáncer $(13,2 \%)$.

En ambos grupos las infecciones fueron la principal causa de MCRF. Las enfermedades 
Tabla 1. Características clínicas en 407 trasplantes renales efectuados entre 1968 - 2010

\begin{tabular}{|c|c|c|c|c|}
\hline & & Grupo $1(n=151)$ & Grupo $2(n=256)$ & $\mathbf{p}$ \\
\hline Edad (años) media (DS) & & $35,1(11,9)$ & $39,6(13,2)$ & $<0,001$ \\
\hline Género (\% masculino) & & 57,7 & 52,7 & NS \\
\hline Donante cadáver & $\mathrm{n}(\%)$ & $49(32,5)$ & $208(81,3)$ & $<0,001$ \\
\hline $\begin{array}{l}\text { Donante vivo } \\
\text { Vivo relacionado } \\
\text { Vivo no relacionado }\end{array}$ & $\begin{array}{l}n(\%) \\
n(\%) \\
n(\%)\end{array}$ & $\begin{array}{r}102(67,5) \\
91 / 102(89,2) \\
11 / 102(10,8)\end{array}$ & $\begin{array}{r}48(18,7) \\
41 / 48(85,4) \\
7 / 48(14,6)\end{array}$ & $\begin{array}{l}<0,001 \\
\text { NS } \\
\text { NS }\end{array}$ \\
\hline Primer trasplante renal & $\mathrm{n}(\%)$ & $146(96,7)$ & $243(94,9)$ & NS \\
\hline Segundo trasplante renal & $n(\%)$ & $4(2,6)$ & $12(4,7)$ & NS \\
\hline Tercer trasplante renal & $n(\%)$ & $1(0,7)$ & $1(0,4)$ & NS \\
\hline PRA máximo > $10 \%$ & $(\%)$ & 31,5 & 29,7 & NS \\
\hline Receptores con DM & $\mathrm{n}(\%)$ & $5(3,4)$ & $16(6,3)$ & NS \\
\hline Injertos que no funcionaron & $n(\%)$ & $19(12,6)$ & $17(6,6)$ & 0,02 \\
\hline Injertos que funcionaron & $n(\%)$ & $132(87,4)$ & $239(93,4)$ & 0,02 \\
\hline Injertos aún funcionantes & $n(\%)$ & $22 / 132(16,7)$ & $166 / 239(69,5)$ & $<0,001$ \\
\hline Injertos que fallaron con el tiempo & $\mathrm{n}(\%)$ & $110 / 132(83,3)$ & $73 / 239(30,5)$ & $<0,001$ \\
\hline Regresaron a diálisis crónica & $\mathrm{n}(\%)$ & $80 / 110(72,7)$ & $34 / 73(46,6)$ & $<0,001$ \\
\hline No aceptaron reingreso a diálisis & $\mathrm{n}(\%)$ & $1 / 110(0,9)$ & $0 / 73(0)$ & NS \\
\hline Fallecieron con injerto funcionante & n (\%) & $29 / 110(26,4)$ & $39 / 73(53,4)$ & $<0,001$ \\
\hline Años totales de observación & & 1.366 & 1.852 & \\
\hline Meses de observación. Promedio (DS) & & $124,1(100,2)$ & $93,0(59,4)$ & $<0,001$ \\
\hline
\end{tabular}

PRA: anticuerpos reactivos contra linfocitos de panel; DM: diabetes mellitus.

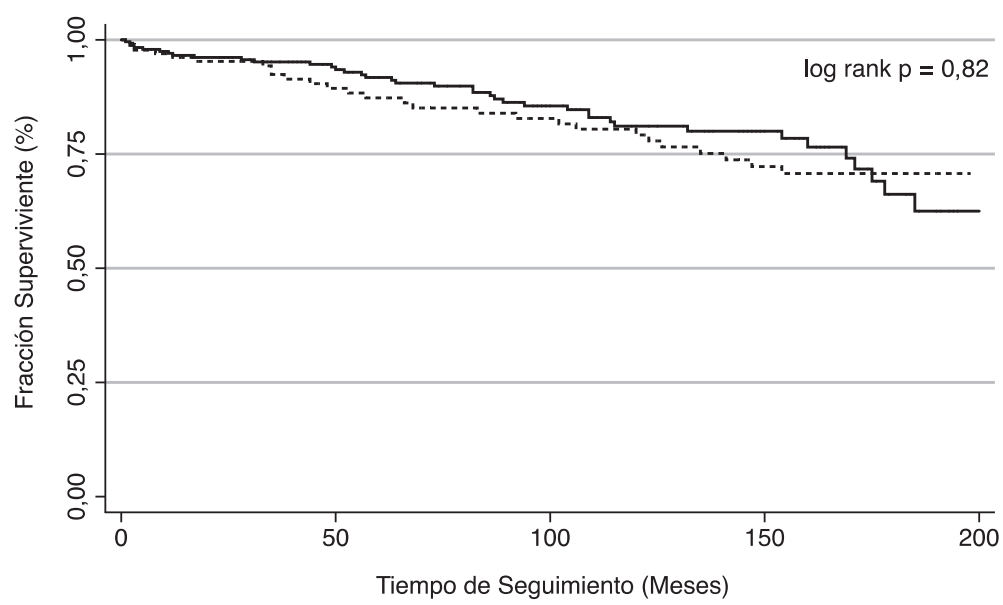

\begin{tabular}{|c|c|c|}
\hline Seguimiento & Grupo 1 (\%) & Grupo 2 (\%) \\
\hline 1 Año & $96 \%$ & $97 \%$ \\
\hline 3 Años & $92 \%$ & $96 \%$ \\
\hline 1 Años & $87 \%$ & $92 \%$ \\
\hline Años & $79 \%$ & $81 \%$ \\
\hline
\end{tabular}

Figura 1. Supervivencia de trasplantados renales por grupos. 
Tabla 2. Función renal durante la evolución del trasplante

\begin{tabular}{|c|c|c|c|}
\hline Características & $\begin{array}{l}\text { Grupo } 1 \\
(n=29)\end{array}$ & $\begin{array}{l}\text { Grupo } 2 \\
(n=39)\end{array}$ & $\mathbf{p}$ \\
\hline Creatininemia al alta del TxR, mg/dl, mediana (RIC) & $1,30(1,10-1,85)$ & $1,60(1,34-2,10)$ & 0,04 \\
\hline Creatininemia al año del TxR,mg/dl, mediana (RIC) & $1,15(0,90-1,71)$ & $1,43(1,19-1,71)$ & 0,08 \\
\hline eGFR al año, ml/min/1,73 m² (MDRD) med. (RIC) & $74(47,5-90,5)$ & $55(40-62)$ & 0,01 \\
\hline Se efectuó biopsia renal post TxR (\%) & 37,9 & 23,1 & NS \\
\hline Última creatininemia ambulatoria, mg/dl, med. (RIC) & $2,14(1,50-3,10)$ & $2,14(1,49-2,97)$ & NS \\
\hline Última eGFR (MDRD), mediana (RIC) & $36,5(19-49)$ & $33,0(20-49)$ & NS \\
\hline Duración del TxR (meses), mediana (RIC) & $66(35-123)$ & $73(19-114)$ & NS \\
\hline Edad al fallecimiento (años), mediana (RIC) & $52(44-60)$ & $56(47-60)$ & NS \\
\hline Muerte ocurrida en el hospital (\%) & 81,5 & 84,2 & NS \\
\hline
\end{tabular}

TxR: Trasplante renal; eGFR: Velocidad de filtración glomerular estimada; med: mediana; RIC: rango intercuartil.

Tabla 3. Causas de muerte con injerto funcionante en $\mathbf{6 8}$ trasplantados renales durante un período de 42 años

\begin{tabular}{|llll|}
\hline & $\begin{array}{l}\text { Grupo 1 } \\
(\mathbf{n}=\mathbf{2 9})\end{array}$ & $\begin{array}{l}\text { Grupo 2 } \\
(\mathbf{n}=\mathbf{3 9})\end{array}$ & $\mathbf{p}$ \\
Infecciones, n (\%) & $11(38,0)$ & $16(41,0)$ & NS \\
- sepsis & 7 & 10 & NS \\
- neumonía & 4 & 5 & NS \\
- encefalitis & 0 & 1 & NS \\
Enfermedades digestivas, n (\%) & $7(24,1)$ & $9(23,1)$ & NS \\
- daño hepático & 4 & 2 & NS \\
- pancreatitis aguda & 1 & 3 & NS \\
- peritonitis & 1 & 2 & NS \\
- diarrea crónica & 1 & 2 & NS \\
Enfermedades cardiovasculares & $6(20,7)$ & $10(25,6)$ & NS \\
- ICC/EPA & 2 & 3 & NS \\
- infarto agudo miocárdico & 1 & 3 & NS \\
- accidentes cerebrovasculares & 1 & 2 & NS \\
- muerte súbita/arritmias/bloqueos & 1 & 1 & NS \\
- trombosis mesentérica & 1 & 0 & NS \\
- embolia pulmonar & 0 & 1 & NS \\
Cáncer & $5(17,2)$ & $4(10,3)$ & NS \\
\hline \hline
\end{tabular}

ICC: insuficiencia cardiaca congestiva; EPA: edema pulmonar agudo. cardiovasculares, digestivas y cánceres fueron responsables de MCRF en porcentajes similares en ambos grupos (Tabla 3). Las causas de MCRF según el tiempo transcurrido desde el TxR fueron semejantes en ambos grupos (Tabla 4).

\section{Fallecidos durante el primer año}

Trece $(19,1 \%)$ sujetos fallecieron en los primeros 12 meses posteriores al TxR. En 7 la muerte estuvo relacionada a reacciones adversas de la terapia inmunosupresora o a complicaciones médico-quirúrgicas del TxR.

Siete pacientes fallecieron dentro de los primeros 3 meses del injerto, 5 por una infección (neumonía, sepsis por Salmonella, infección de un linfocele). Tres habían recibido recientemente terapia anti-rechazo con metilprednisolona y 1 terapia con ganciclovir por una infección a CMV. Tres presentaron una agranulocitosis atribuida al uso de azatioprina en su evento final. Los 2 restantes fallecieron de pancreatitis aguda complicada de absceso y de hemorragia cerebral hipertensiva.

Entre los meses 4 y 12 fallecieron 6 pacientes, 3 por patología abdominal (perforación de divertículo colónico, pancreatitis aguda), 1 por sepsis y 2 por 
Tabla 4. Causas de muerte según el tiempo transcurrido después del trasplante renal

\begin{tabular}{|lcc|}
\hline Intervalos entre TxR y & $\begin{array}{c}\text { Grupo 1 } \\
\text { MCRF }\end{array}$ & $\begin{array}{c}\text { Grupo 2 } \\
(\mathbf{n}=\mathbf{3 9})\end{array}$ \\
1 a 12 meses & $(\mathrm{n}=5)$ & $(\mathrm{n}=8)$ \\
Infecciones & 3 & 3 \\
Enfermedades digestivas & 1 & 3 \\
Enfermedades cardiovasculares & 1 & 2 \\
13 a 36 meses & $(\mathrm{n}=4)$ & $(\mathrm{n}=3)$ \\
Infecciones & 1 & 3 \\
Enfermedades digestivas & 2 & 0 \\
Enfermedades cardiovasculares & 1 & 0 \\
37 a 60 meses & $(\mathrm{n}=5)$ & $(\mathrm{n}=6)$ \\
Infecciones & 2 & 1 \\
Enfermedades digestivas & 1 & 1 \\
Enfermedades cardiovasculares & 1 & 2 \\
Cáncer & 1 & 2 \\
61 a 120 meses & $(\mathrm{n}=7)$ & $(\mathrm{n}=14)$ \\
Infecciones & 3 & 6 \\
Enfermedades digestivas & 1 & 4 \\
Enfermedades cardiovasculares & 1 & 2 \\
Cáncer & 2 & 2 \\
$>>120$ Meses & $(\mathrm{n}=8)$ & $(\mathrm{n}=8)$ \\
Infecciones & 2 & 4 \\
Enfermedades digestivas & 2 & 0 \\
Enfermedades cardiovasculares & 2 & 4 \\
Cáncer & 2 & 0 \\
\hline
\end{tabular}

ECV. De estos últimos, uno presentó una enfermedad tromboembólica masiva y el otro, una hemorragia cerebral masiva.

\section{Fallecidos después del año hasta el tercer año}

Siete sujetos murieron durante este período $(10,3 \%), 3$ durante el segundo año y 4 en el tercero posterior al TxR. Cuatro fallecieron de infecciones (sepsis, neumonía), 2 de cirrosis hepática y el restante, de un edema pulmonar agudo.

\section{Fallecidos después del tercer año hasta los 5 años}

Once pacientes fallecieron durante este período $(16,2 \%), 3$ por un cáncer (estómago, ovario e hígado), 3 de infecciones (sepsis, neumonía), 3 de
ECV (infarto miocárdico, infarto cerebral, muerte súbita) y 2 de causas digestivas (pancreatitis aguda, caquexia por síndrome de mala absorción).

\section{Fallecidos después del quinto año hasta los 10 años}

Veintiuno (30,9\%) de los fallecidos murieron entre el sexto y décimo año del TxR. Las causas de sus muertes fueron infecciones en 9 (sepsis, neumonía, empiema pleural, encefalitis viral), digestivas en 5 (hepatitis fulminante, cirrosis hepática, colitis pseudomembranosa, diarrea crónica), cáncer en 4 (vía biliar, linfoma no Hodgkin, piso de la boca y senos paranasales) y 3 por ECV (edema pulmonar agudo, trombosis mesentérica).

\section{Fallecidos después de los 10 años}

Después de los 10 años de TxR fallecieron 16 $(23,5 \%)$ enfermos. Las causas de muerte fueron ECV en 6 (infarto miocárdico, insuficiencia cardiaca, bloqueo AV completo), infecciosas en 6 (sepsis, neumonía, varicela complicada de sepsis estafilocócica), cáncer en 2 (gástrico, piel) y digestivas (pancreatitis aguda, cirrosis hepática por infección por virus C).

\section{Características de receptores $y$ donantes}

Las edades y género de donantes y receptores no fueron diferentes entre los 2 grupos. En cambio, los donantes cadavéricos y los retrasplantes fueron significativamente más frecuentes en los trasplantados después del año 1992. Los intervalos de tiempo entre el diagnóstico de IRC y su ingreso a DC como los meses transcurridos entre el ingreso a DC y la realización del TxR fueron significativamente menores en el primer grupo de trasplantados (Tabla 5).

Las etiologías de IRC fueron similares en ambos grupos, siendo más frecuentes la glomerulonefritis crónica y las nefropatías de origen desconocido. La prevalencia de portadores del virus $\mathrm{C}$ de la hepatitis fue similar en ambos grupos, en cambio las infecciones por el virus B no ocurrieron en los sujetos del grupo 2 (Tabla 5 ).

No hubo diferencias en la compatibilidad HLA en antígenos Clase I y II entre donantes y receptores entre ambos períodos, sin embargo, la mediana de los PRA fue significativamente más alta en el grupo 2 (Tabla 5).

El esquema inmunosupresor inicial predominante en el primer grupo fue azatioprina $y$ 
prednisona, siendo poco frecuente el uso de un esquema tri-asociado. En el segundo grupo todos recibieron un esquema con tres drogas, que incluyó ciclosporina. La inducción con anticuerpos antilinfocíticos (AAL) o basiliximab fue de baja ocurrencia. La incorporación del micofenolato mofetil o micofenolato de sodio, tacrolimus y sirolimus solo se efectuó en el segundo grupo de trasplantados (Tabla 5).

\section{Complicaciones posteriores al TxR}

Los episodios de rechazo agudo tratados fueron más frecuentes en el grupo 1 y la dosis total utilizada de metilprednisolona mayor. El uso de

Tabla 5. Características demográficas de donantes y receptores, etiologías de la insuficiencia renal crónica e incompatibilidades HLA en $\mathbf{6 8}$ trasplantados fallecidos con un riñón funcionante

\begin{tabular}{|c|c|c|c|}
\hline Característica & Grupo 1 & Grupo 2 & $\mathbf{p}$ \\
\hline Edad donante, años, mediana (RIC) & $35,5(20,5)$ & $35,5(23)$ & NS \\
\hline Edad receptor, años, mediana (RIC) & $47(51-39)$ & $47(53-43)$ & NS \\
\hline Sexo donante, $\%$ masculino & 42,3 & 52,6 & NS \\
\hline Sexo receptor, \% masculino & 65,5 & 51,3 & NS \\
\hline Donante cadavérico, \% & 31,0 & 79,5 & $<0,001$ \\
\hline Donante vivo, \% & 69,0 & 20,5 & $<0,001$ \\
\hline Trasplantes previos, n (\%) & $0(0 \%)$ & $6(15,4 \%)$ & 0,03 \\
\hline Intervalo IRC-HD*, meses, mediana (RIC) & $3(8-1)$ & $9,5(54-3)$ & 0,009 \\
\hline Intervalo HD/TxR**, meses, mediana (RIC) & $9(19-7)$ & $43(68-18)$ & $<0,001$ \\
\hline \multicolumn{4}{|l|}{ Etiología IRC: } \\
\hline - Desconocida, n (\%) & $14(48,3)$ & $12(30,8)$ & NS \\
\hline - Glomerulonefritis crónica, n (\%) & $8(27,6)$ & $11(28,2)$ & NS \\
\hline - Riñones poliquísticos, n (\%) & $3(10,3)$ & $4(10,3)$ & NS \\
\hline - Pielonefritis crónica, n (\%) & $3(10,3)$ & $4(10,3)$ & NS \\
\hline - Nefroesclerosis, n (\%) & $1(3,5)$ & $1(2,6)$ & NS \\
\hline - Nefropatía diabética, n (\%) & $0(0)$ & $4(10,3)$ & 0,13 \\
\hline - Otras, n (\%) & $0(0)$ & $3(7,7)$ & NS \\
\hline Infección por virus $C$ de hepatitis, $n$ (\%) & $3(10,3)$ & $7(18,0)$ & NS \\
\hline Infección por virus B de hepatitis, n (\%) & $5(17,2)$ & $0(0)$ & 0,01 \\
\hline Diabetes mellitus previa al TxR, n (\%) & $0(0)$ & $4(10,3)$ & 0,13 \\
\hline \multicolumn{4}{|l|}{ Inmunología: } \\
\hline \multicolumn{4}{|l|}{ Incompatibilidades HLA A-B } \\
\hline 0 - 2 incompatibilidades, \% & 86,2 & 76,9 & NS \\
\hline 3 - 4 incompatibilidades, \% & 13,8 & 23,1 & NS \\
\hline \multicolumn{4}{|l|}{ Incompatibilidades HLA DR } \\
\hline 0 - 1 incompatibilidades, \% & 87,5 & 92,1 & NS \\
\hline 2 incompatibilidades, \% & 12,5 & 7,9 & NS \\
\hline PRA máximo, \%. mediana (RIC) & $0(6-0)$ & $10(24-2)$ & 0,007 \\
\hline PRA máximo > 10, \% & 24,1 & 43,6 & 0,09 \\
\hline PRA pre TxR, \%. mediana (RIC) & $0(0-0)$ & $0(5-0)$ & 0,1 \\
\hline PRA pre $\operatorname{TxR}>10, \%$ & 10,3 & 15,4 & NS \\
\hline
\end{tabular}

RIC: rango intercuartil; IRC: insuficiencia renal crónica; TxR: trasplante renal; PRA: anticuerpos reactivos contra panel de linfocitos. *Intervalo entre diagnóstico de IRC e inicio de diálisis crónica. ** Intervalo entre inicio de HD y trasplante renal. 
Causas de muerte en trasplantados renales - J. Vega et al

Tabla 6. Inmunosupresión utilizada durante la evolución de los trasplantados renales

\begin{tabular}{|lccc|}
\hline Característica & Grupo 1 & Grupo 2 & p \\
Inmunosupresión inicial & & & \\
Azatioprina - Prednisona (\%) & 79,3 & 0 & $<0,001$ \\
Azatioprina - Prednisona - CsA (\%) & 20,7 & 92,3 & $<0,001$ \\
MMF/AMF - Prednisona - CsA (\%) & 0 & 7,7 & 0,25 \\
Inducción con anticuerpos & 0 & 7,7 & 0,25 \\
TAR durante el primer año del TxR (\%) & 75,9 & 31,6 & $<0,001$ \\
Metilprednisolona gramos utilizados, & 3 & 1,5 & 0,02 \\
mediana (RIC) & $(1,5-4,5)$ & $(1,5-3,0)$ & \\
Uso de anticuerpos antilinfocíticos (\%) & 6,9 & 5,1 & 0,99 \\
TAR años 2 a 5 post TxR (\%) & 41,7 & 16,1 & 0,03 \\
Último esquema inmunosupresor utilizado & & & \\
Azatioprina - Prednisona (\%) & 65,5 & 0 & $<0,001$ \\
Azatioprina - Prednisona - CsA (\%) & 13,8 & 43,6 & 0,016 \\
Ciclosporina - Prednisona (\%) & 17,3 & 25,6 & 0,409 \\
MMF/AMF - CsA - Prednisona (\%) & 0 & 20,0 & 0,017 \\
Otros esquemas (\%) & 3,4 & 12,8 & 0,229 \\
\hline
\end{tabular}

AZA: Azatioprina; PRED: Prednisona; MMF: Micofenolato mofetil; AMF: Micofenolato de sodio. CsA: Ciclosporina; TAR: Terapia antirechazo; TxR: Trasplante renal.

Tabla 7. Complicaciones del trasplante renal en 68 pacientes fallecidos con injerto funcionante

\begin{tabular}{|lrrc|}
\hline Complicaciones & Grupo 1 & Grupo 2 & p \\
\hline Función renal retardada (\%) & 35,7 & 18,4 & 0,12 \\
\hline $\begin{array}{l}\text { Hospitalizaciones por infecciones en primeros } \\
5 \text { años (\%) }\end{array}$ & 34,5 & 35,9 & NS \\
\hline $\begin{array}{l}\text { Enfermedades cardiovasculares en primeros } \\
5 \text { años (\%) }\end{array}$ & 7,1 & 15,4 & NS \\
\hline Neoplasias malignas en primeros 5 años (\%) & 14,3 & 12,8 & NS \\
\hline Diabetes Mellitus post TxR (\%) & 3,5 & 20,5 & 0,06 \\
\hline Daño hepático crónico (\%) & 17,2 & 5,1 & 0,12 \\
\hline Alcoholismo (\%) & 10,3 & 10,3 & NS \\
\hline Eritrocitosis post TxR (\%) & 17,2 & 15,4 & NS \\
\hline Infección por virus varicela-zoster (\%) & 13,8 & 15,4 & NS \\
\hline Infección por citomegalovirus (\%) & 6,9 & 12,8 & NS \\
\hline Tuberculosis (\%) & 6,9 & 2,6 & NS \\
\hline Fracturas óseas (\%) & 10,3 & 12,8 & NS \\
\hline Necrosis ósea avascular (\%) & 3,5 & 7,7 & NS \\
\hline Gota aguda (\%) & 6,9 & 10,3 & NS \\
\hline Hospitalizaciones por infecciones después del & 33,3 & 57,1 & 0,16 \\
\hline $5^{\circ}$ año (\%) & & 28,6 & 0,03 \\
\hline Enfermedades cardiovasculares después del 5 & 0 & 19,1 & 0,14 \\
\hline año (\%) & 46,7 & & \\
\hline Neooplasias malignas después del 5 ${ }^{\circ}$ año (\%) & & & \\
\hline
\end{tabular}

TxR: Trasplante renal.
AAL en la terapia del rechazo y la proporción de enfermos en que se modificó el esquema inmunosupresor durante la evolución del trasplante fue similar en ambos grupos (Tabla 6).

La función renal retardada del injerto no fue significativamente diferente entre los 2 grupos. Un tercio de los pacientes de cada grupo fue hospitalizado por una infección durante los primeros 5 años del trasplante y no hubo diferencias en las infecciones por citomegalovirus, varicela zoster o tuberculosis. Tampoco durante los 5 primeros años hubo diferencias en la incidencia de ECV o neoplasias malignas. Después del quinto año del trasplante hubo una mayor incidencia de pacientes con ECV en el segundo grupo, no así en la aparición de neoplasias malignas ni en las hospitalizaciones por infecciones. La aparición después del trasplante renal de daño hepático crónico, necrosis ósea avascular, fracturas óseas, eritrocitosis, alcoholismo, episodios de gota aguda y diabetes mellitus no fue diferente entre los grupos, aunque hubo una tendencia a una mayor incidencia de diabetes post trasplante en el segundo grupo (Tabla 7).

\section{Discusión}

Se ha definido a la MCRF como el deceso que no ha sido precedido del retorno a DC, nefrectomía del injerto o de rechazo a la prescripción de retornar a diálisis ${ }^{1,4}$. Otros autores han agregado criterios adicionales como una creatinina sérica en la última visita inferior a 4,0 $\mathrm{mg} / \mathrm{dl}$ o han incluido a pacientes que han retornado a diálisis, si 
la muerte ocurrió antes de los 30 días de su reingreso $^{4,15}$. Las 3 primeras condiciones han sido las adoptadas por la mayoría de los autores y son las que utilizamos en este trabajo.

En las estadísticas de TxR, en el cálculo de sobrevida se ha considerado a la MCRF como una falla del injerto. Esto ha sido discutido, argumentándose que ello puede oscurecer el análisis de los datos, especialmente cuando se trata de comparar nuevos esquemas inmunosupresores ${ }^{16,17}$. Claramente hay causas de muerte no relacionadas con el TxR como los accidentes; otras son difíciles de evaluar, como las infecciones o los suicidios. También es discutible considerar como pérdidas de injertos a los pacientes fallecidos por enfermedades cardiovasculares, dado que en forma cada vez más frecuente son trasplantados pacientes de mayor edad y diabéticos, con daño vascular previo importante ${ }^{17,18}$. La MCRF ha llegado a ser la causa predominante de la pérdida tardía de injertos y probablemente su proporción aumente a medida que pacientes de más alto riesgo reciban un $\mathrm{TxR}^{16}$. Por ello, se ha sugerido que en los análisis de sobrevida se consideren por separado, las pérdidas con y sin MCRF ${ }^{16,17,19}$.

La MCRF ha variado entre 5,3\% y $43 \% \%^{1,2,4,5}$, 15,17,18,20-23. En un estudio de 86.502 TxR, 43\% de los sujetos presentaron MCRF. El intervalo entre el TxR y la muerte fue 23 meses y la creatinina previa al fallecimiento $1,9 \mathrm{mg} / \mathrm{dl}^{4}$. En nuestra serie durante el segundo período, la proporción de MCRF fue similar $(53,4 \%)$, también la creatininemia previa al fallecimiento $(2,1 \mathrm{mg} / \mathrm{dl})$. Lo que fue diferente fue el intervalo entre el TxR y la muerte, 66 y 73 meses en cada período, probablemente porque nuestra población de receptores fue más joven y con una menor carga de daño vascular.

La proporción de pérdidas de injertos por MCRF ha ido aumentando progresivamente a través de los años. En un estudio que incluyó a 2.225 TxR separándolos según si fueron efectuados entre 1970-1979, 1980-1989 y 1990-1999; encontró que las MCRF fueron 23,8\%, 31,5\% y 36,9\%, respectivamente ${ }^{15}$. En una serie de $2.578 \mathrm{TxR}$, las pérdidas por MCRF durante los primeros 5 años del TxR aumentaron desde $40 \%$ a $48 \%$ en los períodos 1980-1989 y 1990-1998, respectivamente. Después de los 5 años, la MCRF fue la causa más frecuente de pérdida de injertos ${ }^{5}$. En nuestra serie observamos un fenómeno similar, la proporción de pérdidas de injertos causadas por MCRF se duplicaron en el segundo período. En una comunicación que incluyó a $1.400 \mathrm{TxR}$, el intervalo entre TxR y muerte fue 37 meses. El 9,2\% de los pacientes falleció durante el primer mes, 22,9\% entre el $2^{\circ}$ y $12^{\circ}, 29,8 \%$ entre 13 y 60 meses y $35,1 \%$ después del $5^{\circ}$ año ${ }^{1}$. En nuestra serie las pérdidas por MCRF fueron 3,0\%, $16,2 \%, 26,4 \%$ y $54,4 \%$ en los mismos períodos, respectivamente.

Las causas más frecuentes de MCRF son las ECV, infecciones y cáncer ${ }^{1,2,4}$. Menos frecuentes son las enfermedades hepáticas, gastrointestinales, accidentes y suicidios ${ }^{3,4}$. En el estudio que reunió el mayor número de pacientes, las causas de MCRF más frecuentes fueron las ECV $(42,3 \%)$. Le siguieron en frecuencia las infecciones $(17,6 \%)$, cáncer $(9,2 \%)$, patologías gastrointestinales $(2,1 \%)$ $\mathrm{y}$ accidentes o suicidios $(1,8 \%)^{4}$. En un registro europeo las ECV fueron responsables de $47 \%$ de las MCRF, las infecciones 15\% y los cánceres $15 \%{ }^{3}$.

De las ECV, la cardiopatía coronaria es la causa más frecuente de MCRF, siendo responsable de más de $50 \%$ de las muertes ${ }^{4,6,24}$. En nuestra serie las ECV fueron la segunda causa de MCRF (en proporciones similares a las enfermedades gastrointestinales) siendo superadas por las infecciones. Es probable que en esta menor proporción de muertes por ECV haya influido la menor edad de nuestros trasplantados (37,9 años) y un menor tiempo de permanencia en DC, factor reconocidamente asociado a una ateroesclerosis acelera$\mathrm{da}^{2,4,10,15,20,23,25-27}$.

Las causas de MCRF han ido cambiando con los años. En una serie de 2.225 pacientes trasplantados entre 1970 y 1999, las muertes por ECV aumentaron desde $14 \%$ en la primera década hasta $30,5 \%$ en la tercera. También los fallecimientos causados por accidentes cerebrovasculares aumentaron desde $2,4 \%$ a $8,0 \%$. Las muertes originadas en infecciones, en cambio, cayeron desde 43,3\% a $27,1 \%$ en los mismos períodos ${ }^{15}$. Esto ha sido comunicado en otras series ${ }^{3,4}$. El cáncer ha aumentado también su frecuencia a través del tiempo, comunicándose cifras de hasta $16 \% \%^{3,4,6,22}$. Las muertes por enfermedades hepáticas y gastrointestinales no han tenido variaciones significativas ${ }^{18,22}$. Esto último también ocurrió en nuestra serie.

Las causas de MCRF son también diferentes según el tiempo de evolución del injerto. Durante el primer mes del TxR casi la mitad de las MCRF son por ECV, principalmente infartos cardiacos ${ }^{4}$. Le siguen las infecciones, las que tienen su mayor 
frecuencia en el período comprendido entre los 2 y 12 meses post $\mathrm{TxR}^{1,4,10}$, siendo más comunes las septicemias y neumonías ${ }^{3,22}$. En nuestra serie no observamos variaciones en las causas de muerte según el tiempo de evolución de los injertos. Tampoco tuvimos fallecimientos originados en accidentes o suicidios. Es probable que ello se deba al número reducido de casos con MCRF.

En una serie, $57 \%$ de las muertes por infecciones fueron originadas por bacterias, $25 \%$ por virus y $18 \%$ por hongos ${ }^{28}$. Ellas se ven favorecidas por la inmunosupresión más potente durante los primeros meses del TxR, las terapias anti-rechazo y el empleo de procedimientos quirúrgicos ${ }^{1}$. En nuestra serie, la mayoría de las muertes por infecciones fueron de etiología bacteriana. Sólo en 3 pacientes hubo una infección viral causante de la muerte (varicela complicada de sepsis, neumonía por CMV, encefalitis viral). No observamos infecciones sistémicas por hongos. En esto puede haber jugado un rol el empleo habitual de ketoconazol (como ahorrador de ciclosporina) en todos los pacientes que no tenían contraindicaciones para usarlo.

La incidencia de cáncer en TxR es 3 a 5 veces la de la población general y es responsable de menos de 5\% de las MCRF durante el primer año aumentando a $12 \%$ entre el $2^{\circ}-5^{\circ}$ y a $13 \%$ del $6^{\circ}-10^{\circ}$ año. Después de la década, el cáncer puede ser responsable de hasta $25 \%$ de las muertes ${ }^{4,29}$. En nuestra serie 29,4\% de los pacientes desarrolló un cáncer posterior al TxR y 13,2\% de las muertes fueron originadas por él. Todas ocurrieron después de los 36 meses del TxR.

En suma, en nuestra serie no observamos variaciones en las causas de MCRF en los últimos 18 años respecto a los 25 años anteriores. $\mathrm{Si}$ encontramos en este segundo período una mayor proporción de TxR efectuados con donante cadáver, un diagnóstico más temprano de IRC, un tiempo de espera más prolongado para acceder al TxR, una mayor sensibilización por antígenos HLA y una menor frecuencia de infección por virus $\mathrm{B}$ en los receptores de TxR. Respecto a las complicaciones, observamos una mayor frecuencia de ECV después de los 5 años del TxR. El período de observación de los pacientes trasplantados en los últimos 18 años fue más corto que en los trasplantados en los años precedentes $y$ la proporción de pérdidas de injertos por MCRF significativamente superior.

\section{Referencias}

1. El-Agroudy AE, Back MA, Shehab El-Dein AB, Ghroneim MA. Death with functioning graft in living donor kidney transplantation: analysis of risk factors. Am J Nephrol 2003; 23: 186-93.

2. Tapiawala SN, Tinckman KJ, Cardella CJ, Cattran DC, Cole EH, Kim SJ. Delayed graft function ant the risk for death with a functioning graft. J Am Soc Nephrol 2010; 21: 153-61.

3. Briggs JD. Causes of death after renal transplantation. Nephrol Dial Transplant 2001; 16: 1545-9.

4. Ojo A, Hanson JA, Wolfe RA, Leichtman AB, Agodoa LY, Port FK. Long-term survival in renal transplant recipients with graft function. Kidney Int 2000; 57: 307-13.

5. Arrazola L, Sozen H, Humar A, Uknis M, Papalois V, Matas AJ. Death with function: the next major hurdle. Transplant Proc 2000; 32: 1832.

6. Marcén R. Immunosuppressive drugs in kidney transplantation: impact on patient survival, and incidence of cardiovascular disease, malignancy and infection. Drugs.2009; 69: 2227-43.

7. Pascual M, Theruvath T, Kawai T, Tolkoff-Rubin N, Cosimi AB. Strategies to improve long-term outcomes after renal transplantation. N Engl J Med. 2002; 346: 580-90.

8. Wolfe RA, Ashby VB, Milford EL, Ojo AO, Ettenger RE, Agodoa LY, et al. Comparison of mortality in all patients on dialysis, patients on dialysis awaiting transplantation, and recipients of a first cadaveric transplant. N Engl J Med 1999; 341: 1725-30.

9. Evenepoel P, Vanrenterghem Y. Death with functioning graft-a preventable cause of graft loss. Ann Transplant 2001; 6: 17-20.

10. Arend SM, Mallat MJ, Westendorp RJ, van der Woude FJ, van Es LA. Patient survival after renal transplantation; more than 25 years follow-up. Nephrol Dial Transplant 1997; 12: 1672-9.

11. Levey AS, Stevens LA, Schmid CH, Zhang YL, Castro AF 3rd, Feldman HI, et al; CKD-EPI (Chronic Kidney Disease Epidemiology Collaboration). A new equation to estimate glomerular filtration rate. Ann Intern Med 2009; 150: 604-12.

12. Levey AS, Bosch JP, Lewis JB, Greene T, Rogers N, Roth D. A more accurate accurate method to estimate glomerular filtration rate from serum creatinine: a new prediction equation. Modification of Diet in Renal Disease Study Group. Ann Intern Med 1999; 130: 461-70.

13. Levey AS, Greene T, Kusek JW, Beck GL, MDRD Study Group. A simplified equation to predict glomerular filtration rate from serum creatinine (abstract). J Am Soc Nephrol 2000; 11: 155A. 
14. Cockcroft DW, Gault MH. Prediction of creatinine clearance from serum creatinine.Nephron. 1976; 16: 31-41.

15. Howard RJ, Reed AI, Hemming AW, Van der Werf WJ, Patton PR, Pfaff WW, et al. Graft loss and death: changing causes after kidney transplantation. Transplant Proc 2001; 33: 3416.

16. West M, Sutherland DE, Matas AJ. Kidney transplant recipients who die with functioning grafts: serum creatinine level and cause of death. Transplantation 1996; 62: 1029-30.

17. Hirata M, Cho YW, Cecka JM, Terasaki PI. Patient death after renal transplantation-an analysis of its role in graft outcome. Transplantation 1996; 61: 1479-83.

18. Diethelm AG, Deierhoi MH, Hudson SL, Laskow DA, Julian BA, Gaston RS, et al. Progress in renal transplantation. A single center study of 3359 patients over 25 years. Ann Surg 1995; 221: 446-57.

19. Matas AJ, Gillingham KJ, Sutherland DE. Half-life and risk factors for kidney transplant outcome-importance of death with function. Transplantation 1993; 55: 75761.

20. Stock PG, Barin B, Murphy B, Hanto D, Diego JM, Light $\mathrm{J}$, et al. Outcomes of kidney transplantation in HIVinfected recipients. N Engl J Med 2010; 363: 2004-14.

21. Yoshimura N, Oka T, Nakane Y, Aikawa I, Okamoto M, Akioka $\mathrm{K}$, et al. Long-term results and complications of living related kidney transplantation in a single center. Transplant Proc 2002; 34: 1675-7.

22. Porazko T, Boratyńska M, Patrzalek D, Klinger M, Szyber
P. Causes of death among cadaver kidney graft recipients between 1983 and 2000. Transplant Proc 2002; 34: 2066-7.

23. Kahwaji J, Bunnapradist S, Hsu JW, Idroos ML, Dudek R. Cause of death with graft function among renal transplant recipients in an integrated healthcare system. Transplantation 2011; 91: 225-30.

24. Lindholm A, Albrechtsen D, Frödin L, Tufveson G, Persson NH, Lundgren G. Ischemic heart disease-major cause of death and graft loss after renal transplantation in Scandinavia. Transplantation 1995; 60: 451-7.

25. Aakhus S, Dahl K, Widerøe TE. Cardiovascular morbidity and risk factors in renal transplant patients. Nephrol Dial Transplant 1999; 14: 648-54

26. Chang SH, Russ GR, Chadban SJ, Campbell SB, McDonald SP. Trends in kidney transplantation in Australia and New Zealand, 1993-2004. Transplantation 2007; 84: 611-8.

27. Prommool S, Jhangri GS, Cockfield SM, Halloran PF. Time dependency of factors affecting renal allograft survival. J Am Soc Nephrol 2000; 11: 565-73.

28. Linares L, Cofán F, Cervera C, Ricart MJ, Oppenheimer F, Campistol JM, et al. Infection-related mortality in a large cohort of renal transplant recipients.Transplant Proc 2007; 39: 2225-7.

29. Webster AC, Craig JC, Simpson JM, Jones MP, Chapman JR. Identifying high risk groups and quantifying absolute risk of cancer after kidney transplantation: a cohort study of 15,183 recipients. Am J Transplant 2007; 7: 2140-51 